\title{
A review of the efficacy of atomoxetine in the treatment of attention-deficit hyperactivity disorder in children and adult patients with common comorbidities
}

\author{
This article was published in the following Dove Press journal: \\ Neuropsychiatric Disease and Treatment \\ 3 February 2017 \\ Number of times this article has been viewed
}

\section{David B Clemow' \\ Chris Bushe ${ }^{2}$ \\ Michele Mancini ${ }^{3}$ \\ Michael H Ossipov ${ }^{4}$ \\ Himanshu Upadhyaya'}

'Eli Lilly and Company, Indianapolis, IN, USA; ${ }^{2}$ Eli Lilly, Windlesham, UK; ${ }^{3}$ Eli Lilly Italia S.p.A., Sesto Fiorentino, Italy; ${ }^{4}$ inVentiv Health Clinical, LLC, Blue Bell, PA, USA
Correspondence: David B Clemow Advisor Scientific Communications Strategy, Eli Lilly and Company, Lilly Corporate Center Indianapolis, IN 46285, USA

Tel +| $317276786 \mid$

Email davidclemow@lilly.com

\begin{abstract}
Attention-deficit hyperactivity disorder (ADHD) is a common neuropsychiatric disorder that is often diagnosed during childhood, but has also increasingly been recognized to occur in adults. Importantly, up to $52 \%$ of children (including adolescents) and $87 \%$ of adults with ADHD also have a comorbid psychiatric disorder. The presence of a comorbid disorder has the potential to impact diagnosis and could affect treatment outcomes. Atomoxetine is a nonstimulant treatment for ADHD. Despite numerous published studies regarding efficacy of atomoxetine in the treatment of ADHD in patients with comorbid disorders, there is limited information about the impact of individual common comorbid disorders on the efficacy of atomoxetine for ADHD, especially with regard to adults. Moreover, a cumulative review and assessment of these studies has not been conducted. For this reason, we performed a literature review to find, identify, and cumulatively review clinical studies that examined the efficacy of atomoxetine in the treatment of patients with ADHD and comorbid psychiatric disorders. We found a total of 50 clinical studies ( 37 in children; 13 in adults) that examined the efficacy of atomoxetine in patients with ADHD and a comorbid disorder. The comorbidities that were studied in children or in adults included anxiety, depression, and substance use disorder. Overall, the presence of comorbidity did not adversely impact the efficacy of atomoxetine in treatment of ADHD symptoms in both patient populations. In the studies identified and assessed in this review, atomoxetine did not appear to exacerbate any of the comorbid conditions and could, therefore, be an important therapy choice for the treatment of ADHD in the presence of comorbid disorders.
\end{abstract}

Keywords: comorbid psychiatric disorders, ADHD in children or adolescents, adult attentiondeficit hyperactivity disorder, ADHD

\section{Introduction}

Attention-deficit hyperactivity disorder (ADHD) is a common neuropsychiatric disorder in both children and adults. ${ }^{1}$ The global incidence of ADHD in children (ie, less than 18 years of age) ranges between $5.9 \%$ and $7.1 \%$, and in adults, it ranges between 3\% and 5\%. ${ }^{1-3}$ A considerable proportion of individuals diagnosed with ADHD as children continue to need long-term therapy into adulthood ${ }^{4,5}$ and are at risk for continued difficulties with employment, social interactions, and education, and even have increased mortality risk. ${ }^{4,6,7}$

Complicating the clinical picture of patients with ADHD is the realization that a majority of these patients are likely to have coexisting psychiatric disorders. ${ }^{8-11}$ 
A recent study of 14,825 patients in Danish psychiatric inpatient or outpatient clinics who were between the ages of 4 and 17 years and diagnosed with ADHD for the first time between 1995 and 2010 found that $52 \%$ had at least 1 comorbid disorder and $26 \%$ had 2 or more comorbid disorders. ${ }^{8}$ The incidence of comorbidities in children with ADHD is summarized in Table 1.

It appears that adults with ADHD may have a higher incidence of comorbid disorders than do children. In a large family study, it was found that $87 \%$ of adults with ADHD had at least 1 comorbid psychiatric disorder, and 56\% had at least 2 disorders. ${ }^{22}$ In this study, the most common comorbidities were anxiety, depression, mood disorders, and substance use disorder (SUD). Of note, adult ADHD is under-treated ${ }^{23-25}$ consequently, treatment paradigms for adults, especially in the presence of a comorbid condition, are not as well established as for children, emphasizing the importance of establishing reliable treatment paradigms in this population. The incidence of comorbidities in adults with ADHD is summarized in Table 2. Tables 1 and 2 provide detailed insight into the incidence of each type of comorbidity, and list the comorbidities for which no studies were identified in the literature search.

Table I Incidence of comorbidities with ADHD in children

\begin{tabular}{|c|c|c|}
\hline Comorbidity & Incidence & References \\
\hline \multirow[t]{4}{*}{ Anxiety } & $18 \%$ & Larson et $\mathrm{al}^{10}$ \\
\hline & $25 \%-35 \%$ & Geller et $\mathrm{al}^{12}$ \\
\hline & $25 \%-50 \%$ & Sciberras et $\mathrm{al}^{13}$ \\
\hline & $27 \%$ & Bakken et al ${ }^{14}$ \\
\hline Binge eating & $12 \%$ & Reinblatt et $\mathrm{al}^{15}$ \\
\hline \multirow[t]{3}{*}{ Bipolar disorder } & $0 \%-20 \%$ & Taurines et $\mathrm{al}^{16}$ \\
\hline & $7 \%-22 \%$ & Singh et al $^{17}$ \\
\hline & $5 \%$ & Bakken et al ${ }^{14}$ \\
\hline \multirow[t]{3}{*}{ Conduct disorder/ODD } & $30 \%-50 \%$ & Dopheide and Pliszka ${ }^{3}$ \\
\hline & $40 \%-60 \%$ & Biederman et $\mathrm{al}^{18}$ \\
\hline & $24 \%$ & Bakken et al ${ }^{14}$ \\
\hline \multirow[t]{2}{*}{ Depression } & $21 \%$ & Bakken et $\mathrm{al}^{14}$ \\
\hline & $16 \%-26 \%$ & Gillberg et al ${ }^{19}$ \\
\hline Learning and language & $23 \%$ & Bakken et al ${ }^{14}$ \\
\hline disorders & $46 \%$ & Larson et $\mathrm{al}^{10}$ \\
\hline \multirow[t]{2}{*}{ Obsessive compulsive disorder } & $2 \%$ & Jensen and \\
\hline & & Steinhausen ${ }^{8}$ \\
\hline \multirow{3}{*}{$\begin{array}{l}\text { Pervasive developmental } \\
\text { disorders/ASD }\end{array}$} & $12 \%$ & Jensen and \\
\hline & & Steinhausen $^{8}$ \\
\hline & $30 \%-50 \%$ & Reichow et $\mathrm{al}^{20}$ \\
\hline Substance abuse disorders & $22 \%$ & Kollins $^{21}$ \\
\hline Tic disorders/Tourette's & $7 \%$ & Bakken et al ${ }^{14}$ \\
\hline syndrome & $20 \%-30 \%$ & Taurines et $\mathrm{al}^{16}$ \\
\hline
\end{tabular}

Note: No data were found in the literature for ADHD and antisocial personality disorder in children (ie, $<18$ years of age).

Abbreviations: ADHD, attention-deficit hyperactivity disorder; ASD, autism spectrum disorder; ODD, oppositional defiant disorder.
Table 2 Incidence of comorbidities with ADHD in adults

\begin{tabular}{lll}
\hline Comorbidity & Incidence & Reference \\
\hline Anxiety & $25 \%-35 \%$ & ${\text { Kessler et } \mathrm{al}^{9}}^{9}$ \\
Bipolar disorder & $5 \%-20 \%$ & Perugi and Vannucchi $^{26}$ \\
& $47 \%$ & Wingo and $\mathrm{Ghaemi}^{27}$ \\
& $19 \%$ & Kessler et $\mathrm{al}^{9}$ \\
Depression & $19 \%$ & Kessler et $\mathrm{al}^{9}$ \\
Substance use disorders & $30 \%-50 \%$ & Kolar et al $^{28}$ \\
& $47 \%$ & Kollins $^{21}$ \\
\hline
\end{tabular}

Note: No data were found in the literature for the following comorbidities in adults (ie, $\geq 18$ years of age): antisocial personality disorder, binge eating, conduct disorder/ ODD, learning and language disorders, obsessive compulsive disorder, pervasive developmental disorders/ASD, and tic disorders/Tourette syndrome.

Abbreviations: ADHD, attention-deficit hyperactivity disorder; ASD, autism spectrum disorder; ODD, oppositional defiant disorder.

Although the stimulants, which include various formulations of methylphenidates and amphetamines, provide good efficacy in treating symptoms of ADHD, these drugs are often contraindicated in patients with comorbid disorders, including Tourette's syndrome and bipolar disorder, as well as in patients at risk for substance abuse. ${ }^{30-32}$ Further, some investigators advise caution in prescribing these products to patients with comorbid disorders that are not explicitly contraindicated, such as tic disorders ${ }^{33}$ and anxiety. ${ }^{3,34}$ Suicidal ideation is a symptom that may be present in ADHD patients with comorbid psychiatric disorders, especially depression and bipolar disorder. The presence of suicidal ideation in ADHD patients is a contraindication for methylphenidate in the European Union (EU). ${ }^{32}$ The labeling of both the EU and the US has a warning regarding suicidal ideation in child ADHD patients taking atomoxetine. ${ }^{35-38}$

The selective noradrenergic reuptake inhibitor atomoxetine is approved for the treatment of ADHD in children and adults. ${ }^{6}$ Moreover, it has no abuse potential, and consequently, atomoxetine is considered a first-line therapy for patients at risk for substance abuse disorders. ${ }^{28,39,40}$ In addition, atomoxetine is often preferred over stimulants for patients with ADHD and comorbid tic disorders or anxiety. ${ }^{28,33,40-42}$ Data from recent longer-term studies that incorporate current ADHD trial design concepts also show that there is equivalent efficacy for atomoxetine and methylphenidate, both in adults and children, ${ }^{43,44}$ including data from the most recent updated network meta-analysis. Reported effect sizes for atomoxetine in children with ADHD are consistent with those for the stimulants and range from 0.6 to $1.3 .^{45}$ Effect sizes for atomoxetine in adults were estimated to be 0.40 and 0.41 , which are within the range reported for methylphenidate in adults as well. ${ }^{45}$

Because of the high incidence of psychiatric comorbidities in patients with ADHD, an alternative to stimulants that may be contraindicated due to comorbidities could be warranted 
in some cases. Therefore, understanding the effect of comorbidities on atomoxetine ADHD treatment is clinically relevant. Thus, the aim of this literature review was to provide insight into the effects of comorbid disorders on the efficacy of atomoxetine for the treatment of ADHD symptomology. To the best of our knowledge, there are no comprehensive reviews collectively covering the common ADHD comorbidities in relationship to ADHD treatment for children and adults. The current findings may aid physicians making treatment algorithm decisions that include atomoxetine for patients with ADHD and psychiatric comorbidities.

\section{Methods}

The strategy for the literature search was a thorough review conducted in PubMed. Searches were conducted for (atomoxetine [Title OR Abstract] AND [search term (Title OR Abstract)]). The search was repeated for every item on the list of search terms (Table 3). The searches were limited to articles in English and covering human clinical data (animal data were not included). Each output item was examined for document type (ie, original article, review,

Table 3 Comorbidities and associated terms used in PubMed literature search

\begin{tabular}{|c|c|}
\hline Antisocial personality & Pervasive development \\
\hline disorder & disorder \\
\hline Antisocial & Asperger \\
\hline Personality & Autism \\
\hline Anxiety & Autistic \\
\hline Anxiety & Pervasive \\
\hline Binge eating disorder & PDD \\
\hline Binge & Rett \\
\hline Bipolar disorder & Sleep disorder \\
\hline Bipolar & Hypersomnia \\
\hline Mania & Insomnia \\
\hline Conduct disorder or oppositional & Sleep \\
\hline \multicolumn{2}{|l|}{ defiance disorder } \\
\hline Conduct & Sluggish cognitive tempo \\
\hline Oppositional & Sluggish \\
\hline Defiance & Tempo \\
\hline ODD & SCT \\
\hline Depression & Substance abuse disorder \\
\hline Depression & Abuse \\
\hline Learning disorder or language disorder & Dependence \\
\hline Language & Substance \\
\hline Learning & SUD \\
\hline Dyslexia & Alcohol \\
\hline Reading & Tic disorder \\
\hline Obsessive compulsive disorder & Tic \\
\hline Obsessive & Tourette \\
\hline \multicolumn{2}{|l|}{ Compulsive } \\
\hline OCD & \\
\hline
\end{tabular}

Notes: The search performed was for "atomoxetine" AND the "comorbidity term"; eg, (atomoxetine[Title/Abstract]) AND bipolar[Title/Abstract].

Abbreviations: OCD, obsessive compulsive disorder; ODD, oppositional defiant disorder; PDD, pervasive developmental disorder; SCT, sluggish cognitive tempo; SUD, substance use disorder. case report), and any article that discussed the efficacy of atomoxetine in the treatment of ADHD in patients who also had 1 of the comorbidities was included in this review. Review articles that were discovered by the search were examined and included in the present review if they contained original research results that were not otherwise captured by the literature search. Moreover, only studies that employed validated ADHD rating scales, such as the Attention-Deficit/ Hyperactivity Disorder Rating Scale or the Adult ADHD Self-Report Scale-v1.1, were included. Clinical reports representing results found with a single patient were not included in this review. The searches were not limited by time period. The search terms were selected to cover the common comorbidities, and associated search terms were employed to broaden the search. Further, the general term "anxiety" would return specific disorders such as "social anxiety". Tables 1 and 2 indicate the comorbidities that were found to be common based on the literature search and practical clinical experience. Tables 1 and 2 also provide published estimates of the incidence of these comorbidities in children and adults with ADHD, respectively. It should be noted that, throughout this review, the terms "child" or "children" are used to describe all patients aged less than 18 years. Although some studies might refer to "adolescents", the age ranges tended to vary, and data were not stratified to select age groups other than those aged less than 18 years and 18 years or more. Unless otherwise indicated, the terms "significant" or "significantly" refer to statistical significance.

\section{Results}

The search yielded a total of 50 studies that included ADHD and atomoxetine and at least 1 comorbid disorder. Of these, 37 were in reference to children, whereas 13 were studies performed with adults.

Of the studies performed with children, 23 were doubleblind, placebo-controlled randomized clinical trials (RCTs). Among these 23, there were 3 meta-analyses of RCTs and 4 post hoc subgroup analyses of RCTs. One of the RCTs was preceded by an open-label phase, and another contained an open-label extension. In addition, there were 10 open-label studies, including 4 prospective open-label studies. We also found 2 retrospective chart reviews, 1 retrospective review of medical records, and 1 consecutive case series in this search. No results were returned for atomoxetine in ADHD and antisocial personality disorder, binge eating disorders, or obsessive compulsive disorder in children. The studies on atomoxetine use in children with ADHD and at least 1 comorbid disorder identified in our literature search are summarized in Table 4. 
Table 4 Search results for ADHD and comorbidities in children

\begin{tabular}{|c|c|c|c|}
\hline References & Type of study & Age range & Main findings \\
\hline \multicolumn{4}{|c|}{ Antisocial personality disorder } \\
\hline- & - & - & - \\
\hline \multicolumn{4}{|l|}{ Anxiety } \\
\hline Kratochvil et al ${ }^{46, \#}$ & $\mathrm{RCT}$ & $7-17$ years & $\begin{array}{l}\text { ATX plus PBO not significantly different from ATX and fluoxetine. Significant } \\
\text { improvements in ADHD symptoms (ADHD-RS) and anxiety symptoms } \\
\text { (MASC) }\end{array}$ \\
\hline \multirow[t]{2}{*}{ Geller et al' ${ }^{12}$} & $\mathrm{RCT}$ & $8-17$ years & ATX significantly improved ADHD symptoms (ADHD-RS) and anxiety (PARS)* \\
\hline & & & ATX did not exacerbate comorbid anxiety \\
\hline \multicolumn{4}{|c|}{ Binge eating disorders } \\
\hline- & - & - & - \\
\hline \multicolumn{4}{|l|}{ Bipolar disorder } \\
\hline \multirow[t]{2}{*}{ Chang et $\mathrm{al}^{47}$} & Open-label & $6-17$ years & ATX improved ADHD symptoms \\
\hline & & & $\begin{array}{l}\text { ATX did not change symptoms of depression (CDRS) or of mania (YMRS) in } \\
\text { Pts with ADHD and bipolar disorder }\end{array}$ \\
\hline \multirow[t]{3}{*}{ Hah and Chang ${ }^{48}$} & Consecutive case & & Pts with ADHD and bipolar disorder treated with ATX and mood stabilizers \\
\hline & series & & Six of 7 Pts showed significant improvement in ADHD symptoms \\
\hline & & & No Pts had episodes of hypomania or mania \\
\hline \multicolumn{4}{|c|}{ Conduct disorders and oppositional defiant disorder } \\
\hline \multirow[t]{4}{*}{ Newcorn et $\mathrm{al}^{49}$} & RCT & $8-18$ years & ATX produced clinically meaningful improvements in ADHD (ADHD-RS) and \\
\hline & & & ODD (CPRS-R:S) symptoms \\
\hline & & & Pts with ADHD plus ODD required more ATX than ADHD alone \\
\hline & & & Pts with ADHD plus ODD remained more severely affected \\
\hline \multirow[t]{2}{*}{ Bangs et $\mathrm{a}^{50}$} & $\mathrm{RCT}$ & $6-12$ years & ATX superior to PBO for ODD at 2 and 5 , but not 8 weeks (SNAP-IV ODD) \\
\hline & & & $\begin{array}{l}\text { ATX superior to PBO for ADHD (SNAP-IV ADHD ratings; CGI scales for } \\
\text { severity, improvement, and for the parent version) at } 8 \text { weeks }\end{array}$ \\
\hline \multirow[t]{3}{*}{ Biederman et $a^{18}$} & Meta-analysis of 3 & $6-16$ years & ATX improved ADHD symptoms in Pts with and without ODD (ADHD-RS; \\
\hline & RCTs & & CGI-ADHD-S) \\
\hline & & & $\begin{array}{l}\text { ATX improved ODD (CPRS-R:S oppositional scores), and ODD improvement } \\
\text { correlated with ADHD improvement }\end{array}$ \\
\hline \multirow[t]{3}{*}{ Dittmann et al ${ }^{51}$} & RCT & $6-17$ years & ATX was superior to PBO for ADHD and CD/ODD symptoms (SNAP-IV \\
\hline & & & ADHD and ODD subscales) \\
\hline & & & Path analysis suggests ATX has a specific effect on CD/ODD \\
\hline Dell'Agnello et a $\left.\right|^{52}$ & RCT & $6-15$ years & $\begin{array}{l}\text { ATX was significantly superior to PBO in improving ADHD (SNAP-IV ADHD } \\
\text { subscale; CGI-ADHD-S) and ODD (SNAP-IV ODD subscale) symptoms }\end{array}$ \\
\hline Garg et al ${ }^{53}$ & $\mathrm{RCT}$ & $6-14$ years & $\begin{array}{l}\text { ATX and methylphenidate improved ADHD and ODD symptoms (VADPRS) in } \\
\text { Pts with ADHD and comorbid ODD }\end{array}$ \\
\hline \multirow[t]{2}{*}{ Cheng et $\mathrm{al}^{54, \#}$} & $\begin{array}{l}\text { Meta-analysis of } \\
7 \text { RCTs }\end{array}$ & Not stated & $\begin{array}{l}\text { ATX superior to PBO in reducing ADHD (ADHD-RS-IV; CGI-S; CTRS-R:S) } \\
\text { and ODD symptoms (Oppositional Index of CTRS-R:S) }\end{array}$ \\
\hline & & & $\begin{array}{l}\text { ATX produced smaller changes in ADHD symptoms in Pts with ADHD and } \\
\text { ODD; ATX improved quality of life (CHQ) }\end{array}$ \\
\hline Wehmeier et a $\left.\right|^{55}$ & $\begin{array}{l}\text { Post hoc subgroup } \\
\text { analyses of RCT }\end{array}$ & $6-17$ years & $\begin{array}{l}\text { ATX improved quality of life and self-esteem, in Pts with ADHD and ODD } \\
\text { (KINDL-R) }\end{array}$ \\
\hline Waxmonsky et a ${ }^{56}$ & Open-label & $6-12$ years & $\begin{array}{l}\text { Switching to bid ATX with a slight increase in dose improved ODD, but not } \\
\text { ADHD, symptoms (IOWA Connors Rating Scale) in children with both disorders }\end{array}$ \\
\hline van Wyk et al ${ }^{57}$ & $\begin{array}{l}\text { Meta-analysis of } \\
7 \text { RCTs }\end{array}$ & $6-16$ years & $\begin{array}{l}\text { ATX and methylphenidate produced similar results in Pts with ADHD and } \\
\text { either with or without ODD }\end{array}$ \\
\hline Wehmeier et $\mathrm{a}^{58}$ & $\begin{array}{l}\text { Post hoc subgroup } \\
\text { analyses of RCT }\end{array}$ & $6-12$ years & $\begin{array}{l}\text { ATX reduced severity of ADHD symptoms in Pts with or without ODD/CD } \\
\text { (cb-CPT/MT); ATX had more pronounced effect on hyperactivity in Pts with } \\
\text { comorbid ODD/CD }\end{array}$ \\
\hline Ercan et $\mathrm{a}^{59}$ & $\begin{array}{l}\text { Retrospective chart } \\
\text { review }\end{array}$ & $\begin{array}{l}\text { Mean: } \\
9.97 \pm 1.87 \\
\text { years }\end{array}$ & ATX improved symptoms of ADHD, but not ODD, in Pts with both (CGI) \\
\hline Kaplan et $a^{60}$ & $\begin{array}{l}\text { Post hoc subgroup } \\
\text { analyses of RCT }\end{array}$ & $7-13$ years & $\begin{array}{l}\text { ATX improved ADHD scores (ADHD-RS-IV; CGI-ADHD-S; CPRS-R:S) but } \\
\text { not ODD scores (CPRS-R:S Oppositional subscore) in Pts with both ADHD } \\
\text { and ODD }\end{array}$ \\
\hline Hazell et $\mathrm{a}^{6{ }^{6}}$ & Open-label & $6-15$ years & $\begin{array}{l}\text { ODD did not change relapse rate or latency in Pts with ADHD after ATX } \\
\text { treatment end }\end{array}$ \\
\hline
\end{tabular}


Table 4 (Continued)

\begin{tabular}{|c|c|c|c|}
\hline References & Type of study & Age range & Main findings \\
\hline \multicolumn{4}{|l|}{ Depression } \\
\hline \multirow[t]{2}{*}{ Cheng et a $\left.\right|^{54, \#}$} & Meta-analyses of & Not stated & ATX superior to PBO in reducing ADHD (ADHD-RS-IV; CGI-S; CTRS-R:S) \\
\hline & 7 RCTs & & NNTs were similar for ATX in Pts with and without comorbid depression \\
\hline Scott et $a^{62}$ & $\begin{array}{l}\text { Retrospective chart } \\
\text { review }\end{array}$ & $5-17$ years & $\begin{array}{l}\text { No significant differences in treatment success or treatment failure with ATX } \\
\text { with ADHD and comorbid depression }\end{array}$ \\
\hline Bangs et a ${ }^{63}$ & $\mathrm{RCT}$ & $12-18$ years & $\begin{array}{l}\text { ATX superior to PBO in improving ADHD symptoms (ADHD-RS) } \\
\text { ATX not different from PBO for symptoms of depression (CDRS-R) in Pts } \\
\text { with ADHD comorbid MDD }\end{array}$ \\
\hline \multirow[t]{2}{*}{ Kratochvil et al ${ }^{46, \#}$} & RCT & $7-17$ years & $\begin{array}{l}\text { Marked improvement in ADHD symptoms (ADHD-RS) and depression } \\
\text { symptoms (CDRS-R) }\end{array}$ \\
\hline & & & No difference between ATX + PBO and ATX + fluoxetine \\
\hline Bakken et al $\left.\right|^{14, \#}$ & $\begin{array}{l}\text { Prospective, } \\
\text { observational, } \\
\text { longitudinal, } \\
\text { open-label }\end{array}$ & $6-17$ years & $\begin{array}{l}\text { ATX improved ADHD symptoms (PGI-ADHD-S) in Pts with ADHD with or } \\
\text { without depression } \\
\text { Depressive symptoms improved in } 55 \% \text { of these Pts }\end{array}$ \\
\hline \multicolumn{4}{|c|}{ Learning and language disorders } \\
\hline Wietecha et al ${ }^{64, \#}$ & $\begin{array}{l}\text { RCT with open-label } \\
\text { extension }\end{array}$ & $10-16$ years & $\begin{array}{l}\text { ATX significantly better than PBO in improving ADHD symptoms (ADHD-RS) } \\
\text { in Pts with ADHD and ADHD with comorbid dyslexia } \\
\text { No difference between groups for ADHD symptoms } \\
\text { ATX improved Phonological Loop and Central Executive components of } \\
\text { WMTB-C }\end{array}$ \\
\hline de Jong et al ${ }^{65}$ & $\mathrm{RCT}$ & $8-12$ years & $\begin{array}{l}\text { ATX was similarly effective against ADHD symptoms (ADHD-RS) in Pts with } \\
\text { ADHD alone or ADHD and RD } \\
\text { ATX improved visuospatial working memory (CBTT) and inhibition (SSRT) in } \\
\text { Pts with ADHD and RD, but not with ADHD or RD alone } \\
\text { Note age and IQ differences among groups }\end{array}$ \\
\hline Sumner et al ${ }^{66}$ & Open-label & $10-16$ years & $\begin{array}{l}\text { ATX improved ADHD symptoms (ADHD-RS) and reading scores (K-TEA) in } \\
\text { Pts with ADHD and with or without comorbid dyslexia } \\
\text { Change in WMTB-C central executive score was significantly greater for the } \\
\text { ADHD group } \\
\text { Change in WMTB-C phonological loop score was significantly greater in the } \\
\text { ADHD plus dyslexia group }\end{array}$ \\
\hline Shaywitz et a ${ }^{67}$ & $\begin{array}{l}\text { Open-label, parallel } \\
\text { design }\end{array}$ & $10-16$ years & $\begin{array}{l}\text { ATX produced significant improvements in ADHD symptoms (ADHD-RS) in } \\
\text { Pts with ADHD and those with ADHD and dyslexia } \\
\text { Both groups showed improved reading scores (K-TEA) } \\
\text { Weak correlation between improved ADHD and reading scores }\end{array}$ \\
\hline \multicolumn{4}{|c|}{ Obsessive compulsive disorder } \\
\hline- & - & - & - \\
\hline \multicolumn{4}{|c|}{ Pervasive developmental disorders/autism spectrum disorder } \\
\hline Arnold et a $\left.\right|^{68}$ & $\mathrm{RCT}$ & $\begin{array}{l}5-15 \text { years } \\
\text { (mental age } \\
\geq 18 \text { months) }\end{array}$ & $\begin{array}{l}\text { ATX significantly superior to PBO against hyperactive symptoms of ADHD } \\
\text { (ABC-H; } C G I=I \text { or } 2 \text { ) in Pts with ADHD and ASD } \\
\text { ATX superior (not significant) to PBO against inattentive symptoms of ADHD }\end{array}$ \\
\hline Harfterkamp et al ${ }^{69}$ & $\mathrm{RCT}$ & $6-17$ years & $\begin{array}{l}\text { ATX superior to PBO for symptoms of ADHD (ADHD-RS) in Pts with ADHD } \\
\text { and ASD }\end{array}$ \\
\hline Harfterkamp et al ${ }^{70}$ & Open-label extension & $6-17$ years & $\begin{array}{l}\text { Continued ATX provided continuation of improvement in ADHD symptoms in } \\
\text { Pts with ADHD and ASD }\end{array}$ \\
\hline Troost et $\mathrm{al}^{71}$ & $\begin{array}{l}\text { Open-label } \\
\text { prospective study }\end{array}$ & $6-14$ years & $\begin{array}{l}\text { ATX improved ADHD symptoms in PDD Pts with ADHD symptoms } \\
\text { (ADHD-RS; CPRS-R:S) } \\
\text { ATX improved hyperactivity symptoms in ABC scale }\end{array}$ \\
\hline Fernández-Jaén et a ${ }^{72}$ & $\begin{array}{l}\text { Open-label } \\
\text { prospective study }\end{array}$ & $\begin{array}{l}\text { Mean: } \\
8.7 \pm 3.38 \text { years }\end{array}$ & $\begin{array}{l}\text { ATX improved ADHD symptoms in ADHD Pts with PDD symptoms } \\
\text { (ADHD-RS; CPRS-R:S; CGI) }\end{array}$ \\
\hline Jou et $\mathrm{al}^{73}$ & $\begin{array}{l}\text { Retrospective review } \\
\text { of medical records }\end{array}$ & $6-19$ years & $\begin{array}{l}\text { Pts with PDD showed improvement with ATX in conduct, hyperactivity, } \\
\text { inattention, and learning (CGI) }\end{array}$ \\
\hline Posey et $\mathrm{a}^{74}$ & $\begin{array}{l}\text { Open-label } \\
\text { prospective study }\end{array}$ & $6-14$ years & $\begin{array}{l}\text { Seventy-five percent of ADHD/PDD Pts receiving ATX "much improved" or } \\
\text { "very much improved" on CGI } \\
\text { ATX significantly improved ADHD symptoms on SNAP-IV and ABC-H }\end{array}$ \\
\hline Charnsi $7^{75}$ & Open-label study & $7-15$ years & $\begin{array}{l}\text { Pts with severe ASD and symptoms of ADHD showed no significant } \\
\text { improvement with ATX in hyperactive ADHD symptoms (ABC-H) } \\
\text { ATX improved CGI scores }\end{array}$ \\
\hline
\end{tabular}


Table 4 (Continued)

\begin{tabular}{lll}
\hline References & Type of study & Age range
\end{tabular}

\section{Wietecha et al64:\#}

$10-16$ years

ATX improved K-SCT scores in Pts with ADHD alone or ADHD and dyslexia Positive correlation between improvements in ADHD-RS and in the K-SCT scores: K-SCT Parent subscale score vs ADHDRS-IV-Parent:Inv scores: correlation coefficient: $0.40-0.54, P<0.00$ I K-SCT Teacher subscale score vs ADHDRS-IV-Teacher-Version scores: correlation coefficient: $0.33-0.6 \mathrm{I}, \mathrm{P} \leq 0.004$

K-SCT Youth subscale score vs ADHDRS-Parent:Inv scores: correlation coefficient: $0.16-0.19, P \leq 0.032$

\section{Sleep disorders} Sangal et $\mathrm{al}^{76}$

ATX improved ADHD symptoms (ADHD-RS)

ATX showed significantly shorter latency to sleep vs methylphenidate ATX was associated with less difficulty in falling asleep, waking up, and less irritability (parent and children reports) vs methylphenidate

\section{Substance use disorders}

$\begin{array}{lll}\text { Thurstone et } \text { al }^{77} & \text { Single-site RCT } & \text { 13-19 years }\end{array}$

ATX and PBO improved ADHD symptoms (DSM-IV ADHD symptom checklist)

No difference in ADHD symptoms (DSM-IV ADHD symptom checklist) or nonnicotine substance use in ATX + MI/CBT vs PBO + MI/CBT groups

Bakken et al ${ }^{14, \#} \quad \begin{aligned} & \text { Open-label } \\ & \text { prospective study }\end{aligned}$
Tic disorders/Tourette syndrome

6-17 years ATX reduced symptoms of ADHD (PGI-ADHD-S) in Pts with ADHD No significant improvement in Pts with ADHD and SUD

$\begin{array}{lll}\text { Allen et } \text { al }^{78} & \text { RCT } & 7-17 \text { years }\end{array}$

ATX significantly reduced ADHD symptoms (ADHD-RS) and tic severity (CGI-Tic/Neuro-S)

ATX markedly reduced tics (YGTSS; Tic Symptom Self-Report) in Pts with ADHD and tic disorders

$\begin{array}{ll}\text { Spencer et } \text { al }^{79} & \text { Post hoc subgroup } \\ \text { analyses of RCT } & \text { 7-I7 years }\end{array}$
ATX significantly superior to PBO against ADHD symptoms (ADHD-RS) ATX significantly superior to PBO in reducing tic severity (YGTSS; CGI-Tic/ Neuro-S) in Pts with ADHD and Tourette syndrome Bakken et al ${ }^{14, \#} \quad$ Prospective, 6-17 years observational, ATX significantly improved ADHD symptoms (PGI-ADHD-S) Improved tic disorder in 65\%, no change in 35\% ATX did not worsen tics in Pts with ADHD and tic disorders

Notes: Dashes indicate that no literature results were found on search. \#The source included more than I comorbidity, and appears more than once in the table. Thus, there are 37 articles, 4 of which appear 2 or more times. *A post hoc correlation analysis of this RCT revealed that improvements in anxiety were directly correlated with improvements in symptoms of ADHD. ${ }^{100}$

Abbreviations: ABC, Aberrant Behavior Checklist; ABC-H, Aberrant Behavior Checklist-Hyperactivity Scale; ADHD, attention-deficit hyperactivity disorder; ADHD-RS-IV, Attention-Deficit/Hyperactivity Disorder Rating Scale-IV; ADHDRS-IV-Parent:Inv, ADHD Rating Scale-IV-Parent-Version:Investigator-Administered and Scored; ADHDRSIV-Teacher-Version, ADHD Rating Scale-IV-Teacher-Version; ADHD-RS, Attention-Deficit/Hyperactivity Disorder Rating Scale; ASD, autism spectrum disorder; ATX, atomoxetine; cb-CPT, computer-based continuous performance test; CBTT, Corsi Block Tapping Test; CD, conduct disorder; CDRS, Children's Depression Rating Scale; CDRS-R, Children's Depression Rating Scale-Revised; CGI, Clinical Global Impression; CGI-ADHD-S, Clinical Global Impression-Attention-Deficit Hyperactivity DisorderSeverity; CGI-S, Clinical Global Impression-Severity; CGI-Tic/Neuro-S, CGI Tic/Neurologic Severity Scale; CHQ, Child Health Questionnaire; CPRS-R:S, Conners' Parent Rating Scale-Revised Short Form; CTRS-R:S, Conners' Teacher Rating Scale-Revised Short Form; DSM-IV, Diagnostic and Statistical Manual of Mental Disorders, 4th Edition; IQ, intelligence quotient; KINDL-R, Revidierter KINDer Lebensqualitätsfragebogen; K-SCT, Kiddie-Sluggish Cognitive Tempo; K-TEA, Kaufman Test of Educational Achievement; MASC, Multidimensional Anxiety Scale for Children; MDD, major depressive disorder; MI/CBT, motivational interviewing/cognitive behavioral therapy; MT, infrared motion tracking device; NNTs, numbers needed to treat; ODD, oppositional defiant disorder; PARS, Pediatric Anxiety Rating Scale; PBO, placebo; PDD, pervasive developmental disorder; PGI-ADHD-S, Physician Global Impression: ADHD Severity; Pts, patients; RCT, randomized clinical trial; RD, reading disorder; SNAP-IV, Swanson, Nolan, and Pelham Rating Scale-Revised; SSRT, Stop Signal Reaction Time; SUD, substance use disorder; VADPRS, Vanderbilt ADHD Diagnostic Parent Rating scale; WMTB-C, Working Memory Test Battery for Children; YGTSS, Yale Global Tic Severity Scale; YMRS, Young Mania Rating Scale.

Of the 13 studies that were found with regard to adult patients with ADHD and a comorbidity, 9 were RCTs, including 2 post hoc subgroup analyses. The remaining 4 studies included 3 open-label investigations and a withinsubject retrospective design with naturalistic follow-up. No results were found for atomoxetine-treated adults with ADHD and either antisocial personality disorder, binge eating disorders, bipolar disorder, conduct disorders (CDs), oppositional defiant disorder (ODD), learning and language disorders, obsessive compulsive disorder, pervasive developmental disorders/autism spectrum disorder (ASD), sluggish cognitive tempo (SCT), or sleep disorders. The studies on atomoxetine use in adults with ADHD and at least 1 comorbid disorder identified in our literature search are summarized in Table 5 .

\section{Effects of atomoxetine in children with ADHD and comorbidity}

Anxiety

Anxiety is one of the common comorbidities found in children with ADHD and affects approximately $18 \%$ of children with ADHD, which is substantially greater than the 
Table 5 Search results for ADHD and comorbidities in adults

\begin{tabular}{|c|c|c|c|}
\hline References & Type of study & Age range & Main findings \\
\hline \multicolumn{4}{|c|}{ Antisocial personality disorder } \\
\hline- & - & - & - \\
\hline \multicolumn{4}{|l|}{ Anxiety } \\
\hline \multicolumn{4}{|c|}{ Social anxiety disorder } \\
\hline \multirow[t]{3}{*}{ Adler et $\mathrm{a}^{80}$} & \multirow[t]{3}{*}{ Multicenter RCT } & & ATX significantly better than PBO \\
\hline & & & Response rate better in ADHD (5I\%) than ADHD plus SAD (42\%) \\
\hline & & & CAARS:Inv:SV score improvement better in ADHD than ADHD + SAD \\
\hline Adler et $\mathrm{a}^{|8|}$ & Multicenter RCT & & $\begin{array}{l}\text { ATX significantly improved ADHD symptoms (CAARS:Inv:SV) and } \\
\text { anxiety scores (LSAS; CGI-OS; STAI), and quality of life (AAQoL) } \\
\text { compared to PBO in Pts with ADHD and SAD. SAS was markedly } \\
\text { improved }\end{array}$ \\
\hline Donnelly et a ${ }^{82}$ & $\begin{array}{l}\text { Post hoc subgroup } \\
\text { analyses of RCT }\end{array}$ & & $\begin{array}{l}\text { ATX-mediated improvements in ADHD directly correlated with } \\
\text { anxiety improvement in Pts with ADHD and SAD }\end{array}$ \\
\hline Ravindran et $\mathrm{a}^{83}$ & $\mathrm{RCT}$ & $18-65$ years & $\begin{array}{l}\text { ATX not different from PBO in Pts with GSAD and without ADHD } \\
\text { (LSAS) }\end{array}$ \\
\hline \multicolumn{4}{|c|}{ Generalized anxiety disorder } \\
\hline $\begin{array}{l}\text { Gabriel and } \\
\text { Violato }^{84}\end{array}$ & Open label & $18-65$ years & $\begin{array}{l}\text { ATX as adjunctive to SSRls or to SNRIs improved symptoms of } \\
\text { ADHD (ASRS-vI.I; CGI-S) and anxiety (HAM-A) in Pts with ADHD } \\
\text { and GAD }\end{array}$ \\
\hline Young et al ${ }^{85, \#}$ & $\mathrm{RCT}$ & $\geq 18$ years & $\begin{array}{l}\text { ATX improved ADHD scores, no change in anxiety (STAI) in Pts with } \\
\text { ADHD and without anxiety }\end{array}$ \\
\hline \multicolumn{4}{|c|}{ Binge eating disorders } \\
\hline- & - & - & - \\
\hline \multicolumn{4}{|l|}{ Bipolar disorder } \\
\hline- & - & - & - \\
\hline \multicolumn{4}{|c|}{ Conduct disorders and oppositional defiant disorder } \\
\hline- & - & - & - \\
\hline \multicolumn{4}{|l|}{ Depression } \\
\hline Young et $\mathrm{al}^{85, \#}$ & $\mathrm{RCT}$ & $\geq 18$ years & $\begin{array}{l}\text { ATX was significantly better than PBO in improving ADHD } \\
\text { symptoms (CAARS-Inv:SV), but had no change on depressive } \\
\text { symptoms (MADRS) }\end{array}$ \\
\hline Durell et $\mathrm{a}^{86}$ & $\mathrm{RCT}$ & $18-30$ years & $\begin{array}{l}\text { ATX improved ADHD symptoms (CAARS-Inv:SV), but had no change } \\
\text { on depressive symptoms (MADRS) }\end{array}$ \\
\hline \multicolumn{4}{|c|}{ Learning and language disorders } \\
\hline- & - & - & - \\
\hline \multicolumn{4}{|c|}{ Obsessive compulsive disorder } \\
\hline- & - & - & - \\
\hline \multicolumn{4}{|c|}{ Pervasive developmental disorders/autism spectrum disorder } \\
\hline- & - & - & - \\
\hline \multicolumn{4}{|c|}{ Sluggish cognitive tempo } \\
\hline- & - & - & - \\
\hline \multicolumn{4}{|l|}{ Sleep disorders } \\
\hline- & - & - & - \\
\hline \multicolumn{4}{|c|}{ Substance use disorders } \\
\hline Wilens et $\mathrm{al}^{87}$ & RCT & $\geq 18$ years & $\begin{array}{l}\text { ATX significantly superior to PBO in reducing ADHD symptoms (AISRS) } \\
\text { ATX reduced cumulative days of heavy drinking } \\
\text { ATX did not reduce latency to relapse of heavy drinking }\end{array}$ \\
\hline Wilens et al ${ }^{88}$ & $\begin{array}{l}\text { Post hoc subgroup } \\
\text { analyses of RCT }\end{array}$ & $\geq 18$ years & $\begin{array}{l}\text { Significant correlation between improvements in ADHD symptoms } \\
\text { and reductions in craving for alcohol in ATX, and not PBO, group } \\
\text { PBO, but not ATX, group with relapse to alcohol had significant } \\
\text { worsening of ADHD symptoms }\end{array}$ \\
\hline Benegal et $\mathrm{a}^{89}$ & $\begin{array}{l}\text { Within-subject } \\
\text { retrospective design } \\
\text { with naturalistic } \\
\text { follow-up }\end{array}$ & $27.2 \pm 5.9$ years & $\begin{array}{l}\text { Pts with (72\%) and without DSM-IV ADHD diagnosis } \\
\text { ATX + TAU significantly improved ASRS-vI.I scores, reduced } \\
\text { turnaround time, increased abstinence periods, improved quality of } \\
\text { life, and reduced cigarette smoking vs TAU }\end{array}$ \\
\hline Adler et $\mathrm{al}^{90}$ & Open-label & $36.8 \pm 10.0$ years & $\begin{array}{l}\text { ATX improved ADHD symptoms (AISRS) and significantly reduced } \\
\text { intensity, frequency, and length of cravings (BSCS) in Pts with ADHD } \\
\text { and SUD }\end{array}$ \\
\hline
\end{tabular}


Table 5 (Continued)

\begin{tabular}{|c|c|c|c|}
\hline References & Type of study & Age range & Main findings \\
\hline Levin et $\mathrm{al}^{91}$ & Open-label & $39.3 \pm 6.6$ years & $\begin{array}{l}\text { ATX improved ADHD symptoms (AARS-vI.I) but did not reduce } \\
\text { cocaine use in Pts with ADHD and cocaine dependency }\end{array}$ \\
\hline \multirow[t]{2}{*}{ McRae-Clark et al ${ }^{92}$} & $\mathrm{RCT}$ & 18-65 years & $\begin{array}{l}\text { ATX significantly superior to PBO in treating ADHD symptoms } \\
\text { (CGI-I) }\end{array}$ \\
\hline & & & $\begin{array}{l}\text { ATX and PBO did not reduce cannabis use in Pts with ADHD and } \\
\text { cannabis dependency }\end{array}$ \\
\hline
\end{tabular}

Note: \#Young et a ${ }^{85}$ appears twice, as it addresses more than I comorbidity. Dashes indicate that no literature results were found on search.

Abbreviations: AAQoL, Adult ADHD Quality of Life Scale-29; AARS, Adult ADHD Rating Scale; ADHD, attention-deficit hyperactivity disorder; AISRS, ADHD Investigator Symptom Rating Scale; ASRS-vI.I, Adult ADHD Self-Report Scale-vl.I; ATX, atomoxetine; BSCS, Brief Substance Craving Scale; CAARS:Inv:SV, Conners' Adult ADHD Rating Scale:Investigator-Rated:Screening Version; CGI-I, Clinical Global Impression-Global Improvement; CGI-OS, Clinical Global Impression-Overall Severity; CGI-S, Clinical Global Impression-Severity; DSM-IV, Diagnostic and Statistical Manual of Mental Disorders, 4th Edition; GAD, generalized anxiety disorder; GSAD, generalized social anxiety disorder; HAM-A, Hamilton Anxiety Scale; LSAS, Liebowitz Social Anxiety Scale; MADRS, Montgomery-Åsberg Depression Rating Scale; PBO, placebo; Pts, patients; RCT, randomized controlled trial; SAD, social anxiety disorder; SAS, Social Adjustment Scale; SNRI, selective noradrenergic reuptake inhibitor; SSRI, selective serotonin reuptake inhibitor; STAI, State-Trait Anxiety Inventory; SUD, substance use disorder; TAU, treatment-as-usual.

$2 \%$ incidence reported in children without ADHD. ${ }^{10,93}$ Other studies have estimated the comorbidity of anxiety occurs in $25 \%-50 \%$ of children with ADHD. ${ }^{12,13}$ In spite of the rather large incidence of this comorbidity, only 2 studies were found that addressed the use of atomoxetine in young patients with ADHD and anxiety. ${ }^{12,46}$ In those studies, atomoxetine improved symptoms of ADHD and did not exacerbate anxiety in these patients. Moreover, there was some evidence that symptoms of anxiety were reduced in these patients. ${ }^{12,46}$

\section{Bipolar disorder}

Comorbid bipolar disorder is also a clinical concern, affecting up to $22 \%$ of children with ADHD. ${ }^{16}$ Only 1 open-label study and 1 consecutive case series were found addressing atomoxetine use for ADHD in patients with comorbid bipolar disorder. ${ }^{47,48}$ These studies indicated that atomoxetine improved ADHD symptoms, but not bipolar symptoms, in children with these disorders. Atomoxetine use was not associated with any episodes of mania in these studies. ${ }^{47,48}$

\section{Oppositional defiant disorder}

Both ODD and CD rank among the more common of the comorbidities that present with ADHD, which is a significant concern since they are often associated with worsened ADHD symptoms. ${ }^{50,94}$ A total of 14 studies were found addressing the use of atomoxetine in this patient population (Table 4). Overall, atomoxetine produced significant improvements in symptoms of both ADHD and CD/ODD. In addition, a path analysis suggests that atomoxetine may have a specific effect on CD/ODD. ${ }^{51}$ Interestingly, atomoxetine appeared to have a more pronounced effect on hyperactivity in patients with comorbid ODD/CD, and it was suggested that the presence of this disorder may enhance the efficacy of atomoxetine against symptoms of ADHD. ${ }^{58}$ Atomoxetine also protected against relapse in pediatric ADHD patients with concurrent ODD. ${ }^{61}$

\section{Depression}

Overall, the studies found in this search indicated that atomoxetine was equally effective in reducing symptoms of ADHD in patients with or without comorbid depressive symptoms (Table 4). In 1 RCT with patients who had ADHD with comorbid major depressive disorder, atomoxetine improved ADHD symptoms but did not improve those of major depressive disorder. ${ }^{63}$ A second RCT showed that atomoxetine given alone or with fluoxetine improved both ADHD and depressive symptoms, but no placebo group was included. ${ }^{46}$ In an open-label study, atomoxetine improved ADHD symptoms, and symptoms of depression were improved in 55\% of the patients. ${ }^{14}$ Depressive symptoms were unchanged in 34\% and worsened in $11 \%$ of patients who had comorbid depression, but significance was not reported. ${ }^{14}$

\section{Learning and language disorders}

Dyslexia frequently occurs with ADHD, possibly due to common genetic influences and neuropsychological traits. ${ }^{64}$ The search revealed 2 RCTs and 2 open-label studies that examined the effect of atomoxetine in children with ADHD and a language disorder (Table 4). Overall, atomoxetine was comparable in efficacy against ADHD symptoms in patients with ADHD with or without a learning or language disorder. Importantly, correlation analyses indicated that improvement in ADHD symptoms alone did not explain the improvement in reading scores. ${ }^{67}$

\section{Pervasive developmental disorders/ASD}

The co-occurrence of pervasive developmental disorders, which include ASDs, with ADHD is estimated to range 
between $12 \%$ and $50 \%, 8,20$ and some studies have estimated that as many as $80 \%$ of patients with ADHD have some symptoms of pervasive developmental disorders. ${ }^{19}$ Our search returned 2 blinded, placebo-controlled RCTs, 5 open-label studies, and 1 retrospective examination of patient records addressing atomoxetine and children with ADHD and pervasive developmental disorders or ASD (Table 4). In general, atomoxetine was significantly superior to placebo in treating symptoms of ADHD in this patient population (Table 4). It should be noted that the magnitude of the effect of atomoxetine was reduced compared to studies with children with ADHD without ASD. ${ }^{69}$ However, extending the time-course of atomoxetine administration resulted in continued improvement in ADHD symptoms, suggesting that more time is needed for the full effects of atomoxetine to become established in patients with ADHD and ASD. ${ }^{70}$

\section{Sluggish cognitive tempo}

SCT is an experimental construct rather than a clinical diagnosis that is characterized by drowsiness, daydreaming, lethargy, mental confusion, and slowed thinking/behavior, and it is unclear whether SCT is the inattentive subtype of ADHD or a distinct disorder. ${ }^{95}$ A single double-blind RCT examined the effects of atomoxetine on children with ADHD, dyslexia, or both disorders with regard to SCT symptoms. ${ }^{64}$ Atomoxetine significantly improved SCT symptoms for patients with ADHD alone or ADHD and dyslexia, and also significantly improved the scores of the Parent and Teacher subscales of the Kiddie-Sluggish Cognitive Tempo (K-SCT) for those with dyslexia alone. ${ }^{64}$ While there was a positive correlation (correlation coefficient of 0.40-0.54, $P<0.001$, for K-SCT Parent subscale score with changes in Attention-Deficit/Hyperactivity Disorder Rating ScaleIV-Parent-Version:Investigator-Administered and Scored [ADHDRS-IV-Parent:Inv] scores; correlation coefficient of $0.33-0.61, P \leq 0.004$, for K-SCT Teacher subscale score with changes in Attention-Deficit/Hyperactivity Disorder Rating Scale-IV-Teacher-Version scores; correlation coefficient of $0.16-0.19, P \leq 0.032$, for K-SCT Youth subscale score with changes in ADHDRS-IV-Parent:Inv scores) between improvements in ADHD rating scale and in the K-SCT scores, it appears that changes in ADHD symptoms did not fully drive improvements in SCT. ${ }^{64}$

\section{Sleep disorders}

Children with ADHD have shorter sleep time, longer interrupted sleep time, greater difficulty waking up, and more daytime sleepiness than healthy children. ${ }^{96}$ One RCT
(Table 4) showed that atomoxetine slightly shortened latency to sleep onset and children had less difficulty in falling asleep or waking up and were less irritable. ${ }^{76}$

\section{Substance use disorders}

Although SUD comorbid with ADHD is a clinical concern even in youths, our search returned only $1 \mathrm{RCT}^{77}$ and 1 open-label prospective study ${ }^{14}$ regarding atomoxetine in this patient population (Table 4). Atomoxetine, in combination with motivational interviewing/cognitive behavioral therapy (MI/CBT), was not different from placebo and MI/CBT in improving ADHD symptoms or substance use in patients with ADHD and SUD. ${ }^{77}$ The lack of significant difference between the groups was attributed to a large effect from placebo and/or MI/CBT. In the open-label prospective study, only those patients with ADHD and SUD failed to show significant improvement of ADHD symptoms. ${ }^{14}$

\section{Tic disorders/Tourette's syndrome}

A total of 2 RCTs and 1 prospective, observational openlabel study were found to address the activity of atomoxetine on child patients with ADHD and tic disorders, including Tourette syndrome (Table 4). One RCT showed that atomoxetine was associated with a significant improvement in ADHD symptoms, and some evidence suggests a reduction in tic severity. ${ }^{78}$ A subgroup analysis of patients with comorbid Tourette syndrome from this study showed similar results. ${ }^{79}$ In the open-label study, atomoxetine use was associated with reported improvement in the tic disorder in $65 \%$ of the patients, and no change in the remainder (ie, no patients reported a worsening of tic disorder). ${ }^{14}$

\section{Effects of atomoxetine in adults with ADHD and anxiety}

\section{Anxiety}

We found 4 RCTs, an open-label study, and a post hoc correlation analysis of an RCT when searching for atomoxetine with ADHD and anxiety in adults (Table 5). Of these 6 reports, 3 RCTs addressed social anxiety disorder (SAD), ${ }^{80-82} 1$ RCT addressed generalized social anxiety disorder (GSAD), ${ }^{83}$ and 2 addressed generalized anxiety disorder (GAD) ${ }^{84}$ In these reports, atomoxetine improved symptoms of ADHD in individuals with the disorder with or without either of the comorbid anxiety disorders. In addition, atomoxetine reduced symptoms of anxiety in patients with ADHD and with SAD, GSAD, or GAD (Table 5). Response rates or changes in severity of ADHD symptoms were also significantly greater in patients with ADHD compared to 
those with $\mathrm{ADHD}$ and $\mathrm{SAD},{ }^{80}$ which is consistent with reports that anxiety in general is often associated with a greater severity of ADHD symptoms. ${ }^{97}$ Importantly, atomoxetine produced improvements or no change in anxiety scores of patients with ADHD but with no diagnosis of anxiety disorders. ${ }^{85}$

\section{Depression}

Although depression with ADHD is a common occurrence, ${ }^{9,28}$ we found only 2 RCTs on atomoxetine in adults with ADHD and depression (Table 5). In both studies, atomoxetine significantly improved ADHD symptoms, but did not produce changes in assessments of depression. ${ }^{85,86}$

\section{Substance use disorders}

The presence of SUD in patients with ADHD is an important clinical concern, occurring up to 4 times the incidence observed in individuals without ADHD. ${ }^{98}$ This search yielded 2 RCTs, a post hoc subgroup analysis of 1 of the RCTs, 2 open-label studies, and a retrospective study with a naturalistic follow-up (Table 5). Atomoxetine significantly improved ADHD symptoms in individuals with ADHD in each of these studies. However, results with substance abuse were mixed. Atomoxetine significantly reduced cumulative days of heavy drinking, but did not reduce the latency to relapse of heavy drinking. ${ }^{87}$ A subgroup analysis from this study found a significant correlation between improvements in ADHD symptoms and reductions in cravings for alcohol in atomoxetine-treated patients and not in the placebo group, and those that relapsed showed worsening of ADHD symptoms. ${ }^{88}$ In contrast, both atomoxetine and placebo did not change cannabis use in an RCT of patients with ADHD who were also using cannabis. ${ }^{92}$

An open-label study of adult patients with ADHD and cocaine use showed that atomoxetine significantly improved ADHD symptoms, but did not change cocaine use. ${ }^{91}$ A later open-label study with adult patients with ADHD and polysubstance use (cocaine, cannabis, alcohol, and opioids were the primary abused substances) reported that atomoxetine treatment decreased intensity, frequency, and length of cravings based on the Brief. Substance Craving Scale, each of these dimensions of craving was scored from 0 to $4 .^{90}$

However, atomoxetine did not reduce the number of times that participants thought that they had a craving within the past 24 hours..$^{90}$ A retrospective study of patients with SUD, with $(72 \%)$ or without $(28 \%)$ ADHD, receiving atomoxetine plus treatment-as-usual (TAU) reported a significant reduction in measures of nicotine use when compared to the
TAU-alone group. ${ }^{89}$ However, results were presented for the entire group, and not separated by presence or absence of ADHD. ${ }^{89}$

\section{Discussion}

The 50 studies included in this review suggest that atomoxetine is as effective in treating ADHD symptoms in both child and adult patients with ADHD with comorbid psychiatric conditions as those with ADHD without comorbidities. Although ADHD in children has been described for over a century, the same condition in adults has not received serious attention until the $1990 \mathrm{~s} .{ }^{9}$ It is therefore not surprising that we found 37 studies referencing young patients compared to 13 for adult patients for this review.

Anxiety, depression, mania, and tics have been reported as adverse events in patients taking atomoxetine. ${ }^{37,38}$ However, the atomoxetine product label also states that clinical trials have reported that atomoxetine improves symptoms of ADHD in patients with comorbid anxiety and tic disorders, without worsening these comorbid symptoms..$^{37,38}$ In the studies reviewed, atomoxetine improved various ADHD symptoms in cohorts with and without comorbidities. This observation is supported by a recent systematic review of 24 studies (RCTs and within-subject designs) that concluded that the presence of a comorbidity did not lessen the efficacy of atomoxetine in treating ADHD symptoms. ${ }^{99}$ Importantly, this systematic review did not make clear that in both adults and children, the efficacy of atomoxetine is similar to stimulants and hence atomoxetine has an important role in ADHD treatment for many patients with and without comorbid disorders. ${ }^{43,44}$

In the studies reviewed, there is no evidence of worsening of any of the comorbidities examined, and in some cases, there is significant improvement. It is important however to differentiate usage of atomoxetine when a comorbidity is present from usage in that comorbid condition alone. Atomoxetine does not improve symptoms of anxiety in patients with anxiety disorders but without ADHD. For example, a placebo-controlled RCT showed that atomoxetine was no different from placebo in improving anxiety scores in patients with GSAD. ${ }^{83}$ A post hoc correlation analysis of an RCT of ADHD patients with SAD who were treated with atomoxetine revealed that improvements in anxiety were directly correlated with improvements in symptoms of ADHD. ${ }^{100}$ Moreover, atomoxetine did not exacerbate comorbid anxiety. ${ }^{100}$ It is therefore likely that when improvements in anxiety symptoms are seen, it is probably related to improvement of ADHD symptoms. 
Depression is an important clinical concern in patients with ADHD, as it occurs at a 5 -fold greater incidence in these patients than in the population at large. ${ }^{101} \mathrm{~A}$ link between depression and ADHD is suggested by imaging studies that show that these 2 disorders share common brain regions and neural pathways. ${ }^{102}$ In comorbid patients treated with atomoxetine, it is likely that reported improvements in depressive symptoms result from an improvement in ADHD, and not from a direct antidepressant effect of atomoxetine. This interpretation is consistent with the RCTs that showed that atomoxetine does not act as an antidepressant. ${ }^{103-106}$ The studies in which depression was comorbid with ADHD showed that the presence of depressive symptoms did not adversely impact the efficacy of atomoxetine against ADHD.

Although tics are listed as a possible adverse event with atomoxetine, several treatment guidelines indicate that atomoxetine is preferred over the stimulants for patients with ADHD and comorbid tic disorders. The European ADHD Guidelines Group concluded that the stimulants could worsen comorbid tics, whereas atomoxetine significantly improves them. ${ }^{107}$ The National Institute for Health and Care Excellence (NICE) suggests atomoxetine or methylphenidate when tic disorders or Tourette syndrome is present. ${ }^{108}$

Both child and adult patients with ADHD are at a higher risk of SUD. ${ }^{29,109,110}$ There is an approximately 4 -fold greater incidence of SUD in adult ADHD patients compared to individuals without ADHD.$^{98}$ Despite variable evidence for the role of stimulants in the management of SUD among patients with ADHD, there exists a clinical concern regarding the use of the psychostimulants in patients with SUD, since these drugs show some abuse liability. ${ }^{98,110}$ In contrast, atomoxetine has no abuse liability, ${ }^{111}$ and thus often will be a first-choice treatment in patients with concern for SUD. ${ }^{111}$ Treatment guidelines suggest the use of atomoxetine or of extended-release formulations of methylphenidate in this population to reduce abuse liability. ${ }^{107,112,113}$

Although atomoxetine may be preferable over other treatments for ADHD in the presence of certain psychiatric comorbidities described, there remains reluctance among some clinicians to administer atomoxetine first because of perceptions that it may be less effective. However, a recent systematic review and a network meta-analysis have shown similar efficacy for responders. ${ }^{43,44}$ Many RCTs specifically exclude patients with specific comorbid disorders such as major depressive disorder and anxiety. Our search found clinical studies addressing only 3 comorbid disorders in adults: anxiety, depression, and SUD. There are more studies performed with children, but no data were found with regard to antisocial personality disorder, binge eating disorders, or obsessive compulsive disorder. While it is known that adults with ADHD have irregular sleep-wake cycles and disrupted sleep patterns, we found no studies addressing the effect of atomoxetine on sleep in adults with ADHD, and only 1 study on children with ADHD. Overall, although there is an association of binge eating disorder with ADHD, ${ }^{114}$ there is currently a dearth of evidence as to its incidence, and little guidance on appropriate therapy. There is an appreciable level of comorbidity of bipolar disorder with ADHD. Estimates of comorbid bipolar disorder range up to $22 \%$ of children with ADHD,${ }^{16}$ and as high as $47 \%$ in adults. ${ }^{27}$ In spite of these estimates, there are few studies on the treatment of individuals with ADHD and bipolar disorder. ${ }^{115}$ Care should be taken in treating ADHD patients with comorbid bipolar disorder because of concern for possible induction of a mixed/manic episode. ${ }^{37}$ This cumulative review and analysis of studies of atomoxetine in patients with common comorbidities should help improve current treatment guidelines for ADHD.

\section{Limitations}

An important limitation of this review is that the activity of atomoxetine in ADHD with some comorbid disorders is not well examined. Whereas some of these conditions are subjected to rigorous placebo-controlled, double-blind RCTs, some, such as ODD, are lacking in such studies because individuals with these comorbidities are often excluded from ADHD clinical trials. Also, there are only a few head-to-head comparisons of atomoxetine vs methylphenidate or the other psychostimulants in ADHD patients with common comorbidities. A limitation of this analysis is that it is not a systematic review.

\section{Summary and conclusion}

Overall, atomoxetine shows good efficacy in improving symptoms of ADHD in children and adults. Based on the studies reported in the present review, the presence of comorbid psychiatric disorders does not appear to alter the efficacy of atomoxetine in treating ADHD. Moreover, atomoxetine may be preferable to psychostimulants in the treatment of ADHD in the presence of psychiatric disorders contraindicated for stimulants, while providing similar levels of efficacy and tolerability.

\section{Acknowledgments}

Angela Lorio and Meghana Kuntla of inVentiv Health Clinical, LLC, provided editorial assistance. Eli Lilly and Company contracted inVentiv Health Clinical, LLC, for writing and editorial services. 


\section{Disclosure}

This work was sponsored and funded by Eli Lilly and Company, Indianapolis, IN, USA, and/or any of its subsidiaries. David Clemow and Himanshu Upadhyaya are employed by Eli Lilly and Company, Michele Mancini is employed by Eli Lilly Italia S.p.A, Chris Bushe is employed by Eli Lilly, UK, and Michael Ossipov is employed by inVentiv Health Clinical, LLC.

\section{References}

1. Moffitt TE, Houts R, Asherson P, et al. Is adult ADHD a childhoodonset neurodevelopmental disorder? Evidence from a four-decade longitudinal cohort study. Am J Psychiatry. 2015;172(10):967-977.

2. Willcutt EG. The prevalence of DSM-IV attention-deficit/hyperactivity disorder: a meta-analytic review. Neurotherapeutics. 2012;9(3): 490-499.

3. Dopheide JA, Pliszka SR. Attention-deficit-hyperactivity disorder: an update. Pharmacotherapy. 2009;29(6):656-679.

4. Brod M, Pohlman B, Lasser R, Hodgkins P. Comparison of the burden of illness for adults with ADHD across seven countries: a qualitative study. Health Qual Life Outcomes. 2012;10:47.

5. Faraone SV, Biederman J, Mick E. The age-dependent decline of attention deficit hyperactivity disorder: a meta-analysis of follow-up studies. Psychol Med. 2006;36(2):159-165.

6. Adler LA, Spencer T, Brown TE, et al. Once-daily atomoxetine for adult attention-deficit/hyperactivity disorder: a 6-month, double-blind trial. J Clin Psychopharmacol. 2009;29(1):44-50.

7. Upadhyaya H, Adler LA, Casas M, et al. Baseline characteristics of European and non-European adult patients with attention deficit hyperactivity disorder participating in a placebo-controlled, randomized treatment study with atomoxetine. Child Adolesc Psychiatry Ment Health. 2013;7(1):14

8. Jensen CM, Steinhausen HC. Comorbid mental disorders in children and adolescents with attention-deficit/hyperactivity disorder in a large nationwide study. Atten Defic Hyperact Disord. 2015;7(1):27-38.

9. Kessler RC, Adler L, Barkley R, et al. The prevalence and correlates of adult ADHD in the United States: results from the National Comorbidity Survey Replication. Am J Psychiatry. 2006;163(4):716-723.

10. Larson K, Russ SA, Kahn RS, Halfon N. Patterns of comorbidity, functioning, and service use for US children with ADHD, 2007. Pediatrics. 2011;127(3):462-470.

11. Newcorn JH, Weiss M, Stein MA. The complexity of ADHD: diagnosis and treatment of the adult patient with comorbidities. CNS Spectr. 2007;12(8 Suppl 12):1-14.

12. Geller D, Donnelly C, Lopez F, et al. Atomoxetine treatment for pediatric patients with attention-deficit/hyperactivity disorder with comorbid anxiety disorder. J Am Acad Child Adolesc Psychiatry. 2007;46(9): 1119-1127.

13. Sciberras E, Lycett K, Efron D, Mensah F, Gerner B, Hiscock H. Anxiety in children with attention-deficit/hyperactivity disorder. Pediatrics. 2014;133(5):801-808.

14. Bakken RJ, Paczkowski M, Kramer HP, et al. Effects of atomoxetine on attention-deficit/hyperactivity disorder in clinical pediatric treatment settings: a naturalistic study. Curr Med Res Opin. 2008;24(2):449-460.

15. Reinblatt SP, Leoutsakos JM, Mahone EM, Forrester S, Wilcox HC, Riddle MA. Association between binge eating and attention-deficit/ hyperactivity disorder in two pediatric community mental health clinics. Int J Eat Disord. 2015;48(5):505-511.

16. Taurines R, Schmitt J, Renner T, Conner AC, Warnke A, Romanos M. Developmental comorbidity in attention-deficit/hyperactivity disorder. Atten Defic Hyperact Disord. 2010;2(4):267-289.

17. Singh MK, DelBello MP, Kowatch RA, Strakowski SM. Co-occurrence of bipolar and attention-deficit hyperactivity disorders in children. Bipolar Disord. 2006;8(6):710-720.
18. Biederman J, Spencer TJ, Newcorn JH, et al. Effect of comorbid symptoms of oppositional defiant disorder on responses to atomoxetine in children with ADHD: a meta-analysis of controlled clinical trial data. Psychopharmacology (Berl). 2007;190(1):31-41.

19. Gillberg C, Gillberg IC, Rasmussen P, et al. Co-existing disorders in ADHD - implications for diagnosis and intervention. Eur Child Adolesc Psychiatry. 2004;13 Suppl 1:I80-I92.

20. Reichow B, Volkmar FR, Bloch MH. Systematic review and metaanalysis of pharmacological treatment of the symptoms of attentiondeficit/hyperactivity disorder in children with pervasive developmental disorders. J Autism Dev Disord. 2013;43(10):2435-2441.

21. Kollins SH. ADHD, substance use disorders, and psychostimulant treatment: current literature and treatment guidelines. J Atten Disord. 2008;12(2):115-125.

22. McGough JJ, Smalley SL, McCracken JT, et al. Psychiatric comorbidity in adult attention deficit hyperactivity disorder: findings from multiplex families. Am J Psychiatry. 2005;162(9):1621-1627.

23. Biederman J. Attention-deficit/hyperactivity disorder: a life-span perspective. J Clin Psychiatry. 1998;59 Suppl 7:4-16.

24. Ramos-Quiroga JA, Nasillo V, Fernández-Aranda F, Casas M. Addressing the lack of studies in attention-deficit/hyperactivity disorder in adults. Expert Rev Neurother. 2014;14(5):553-567.

25. Wilens TE, Morrison NR, Prince J. An update on the pharmacotherapy of attention-deficit/hyperactivity disorder in adults. Expert Rev Neurother. 2011;11(10):1443-1465.

26. Perugi G, Vannucchi G. The use of stimulants and atomoxetine in adults with comorbid ADHD and bipolar disorder. Expert Opin Pharmacother. 2015;16(14):2193-2204.

27. Wingo AP, Ghaemi SN. A systematic review of rates and diagnostic validity of comorbid adult attention-deficit/hyperactivity disorder and bipolar disorder. J Clin Psychiatry. 2007;68(11):1776-1784.

28. Kolar D, Keller A, Golfinopoulos M, Cumyn L, Syer C, Hechtman L. Treatment of adults with attention-deficit/hyperactivity disorder. Neuropsychiatr Dis Treat. 2008;4(2):389-403.

29. Biederman J. Attention-deficit/hyperactivity disorder: a selective overview. Biol Psychiatry. 2005;57(11):1215-1220.

30. Adderall $^{\circledR}$ (dextroamphetamine saccharate, amphetamine aspartate, dextroamphetamine sulfate and amphetamine sulfate tablets) [prescribing information]. Horsham, PA: Teva Pharmaceuticals USA; 2015.

31. Ritalin ${ }^{\circledR}$ (methylphenidate hydrochloride tablets) [prescribing information]. Gainesville, GA: Novartis Pharmaceuticals Corporation; 2007.

32. Ritalin ${ }^{\circledR}$ (methylphenidate hydrochloride tablets) [summary of product characteristics]. Surrey: Novartis Pharmaceuticals UK Ltd; 2015.

33. Felt BT, Biermann B, Christner JG, Kochhar P, Harrison RV. Diagnosis and management of ADHD in children. Am Fam Physician. 2014;90(7): 456-464.

34. Coughlin CG, Cohen SC, Mulqueen JM, Ferracioli-Oda E, Stuckelman ZD, Bloch MH. Meta-analysis: reduced risk of anxiety with psychostimulant treatment in children with attention-deficit/ hyperactivity disorder. J Child Adolesc Psychopharmacol. 2015;25(8): 611-617.

35. Bangs ME, Tauscher-Wisniewski S, Polzer J, et al. Meta-analysis of suicide-related behavior events in patients treated with atomoxetine. J Am Acad Child Adolesc Psychiatry. 2008;47(2):209-218.

36. Garnock-Jones KP, Keating GM. Atomoxetine: a review of its use in attention-deficit hyperactivity disorder in children and adolescents. Paediatr Drugs. 2009;11(3):203-226.

37. Strattera ${ }^{\circledR}$ (atomoxetine capsules) [strattera prescribing information]. Indianapolis, IN: Eli Lilly and Company; 2009.

38. Strattera ${ }^{\mathbb{B}}$ (atomoxetine capsules) [strattera summary of product characteristics]. Hampshire: Eli Lilly and Company Ltd.; 2015.

39. Wilens TE. Impact of ADHD and its treatment on substance abuse in adults. J Clin Psychiatry. 2004;65 Suppl 3:38-45.

40. Bolea-Alamañac B, Nutt DJ, Adamou M, et al; British Association for Psychopharmacology. Evidence-based guidelines for the pharmacological management of attention deficit hyperactivity disorder: update on recommendations from the British Association for Psychopharmacology. J Psychopharmacol. 2014;28(3):179-203. 
41. Canadian Attention Deficit Hyperactivity Disorder Resource Alliance (CADDRA). Pharmacological treatment of ADHD. In: Canadian ADHD Practice Guidelines. 3rd ed. Toronto, ON: CADDRA; 2014

42. Weiss MD, Weiss JR. A guide to the treatment of adults with ADHD. J Clin Psychiatry. 2004;65 Suppl 3:27-37.

43. Bushe C, Day K, Reed V, et al. A network meta-analysis of atomoxetine and osmotic release oral system methylphenidate in the treatment of attention-deficit/hyperactivity disorder in adult patients. J Psychopharmacol. 2016;30(5):444-458.

44. Bushe CJ, Savill NC. Systematic review of atomoxetine data in childhood and adolescent attention-deficit hyperactivity disorder 2009-2011: focus on clinical efficacy and safety. $J$ Psychopharmacol. 2014;28(3): 204-211.

45. Clemow DB, Bushe CJ. Atomoxetine in patients with ADHD: a clinical and pharmacological review of the onset, trajectory, duration of response and implications for patients. J Psychopharmacol. 2015;29(12): 1221-1230.

46. Kratochvil CJ, Newcorn JH, Arnold LE, et al. Atomoxetine alone or combined with fluoxetine for treating ADHD with comorbid depressive or anxiety symptoms. J Am Acad Child Adolesc Psychiatry. 2005;44(9): 915-924.

47. Chang K, Nayar D, Howe M, Rana M. Atomoxetine as an adjunct therapy in the treatment of co-morbid attention-deficit/hyperactivity disorder in children and adolescents with bipolar I or II disorder. $J$ Child Adolesc Psychopharmacol. 2009;19(5):547-551.

48. Hah M, Chang K. Atomoxetine for the treatment of attention-deficit/ hyperactivity disorder in children and adolescents with bipolar disorders. J Child Adolesc Psychopharmacol. 2005;15(6):996-1004.

49. Newcorn JH, Spencer TJ, Biederman J, Milton DR, Michelson D. Atomoxetine treatment in children and adolescents with attention-deficit/ hyperactivity disorder and comorbid oppositional defiant disorder. J Am Acad Child Adolesc Psychiatry. 2005;44(3):240-248.

50. Bangs ME, Hazell P, Danckaerts M, et al; Atomoxetine ADHD/ODD Study Group. Atomoxetine for the treatment of attention-deficit/ hyperactivity disorder and oppositional defiant disorder. Pediatrics. 2008;121(2):e314-e320

51. Dittmann RW, Schacht A, Helsberg K, et al. Atomoxetine versus placebo in children and adolescents with attention-deficit/hyperactivity disorder and comorbid oppositional defiant disorder: a double-blind, randomized, multicenter trial in Germany. J Child Adolesc Psychopharmacol. 2011;21(2):97-110.

52. Dell'Agnello G, Maschietto D, Bravaccio C, et al; LYCY Study Group. Atomoxetine hydrochloride in the treatment of children and adolescents with attention-deficit/hyperactivity disorder and comorbid oppositional defiant disorder: a placebo-controlled Italian study. Eur Neuropsychopharmacol. 2009;19(11):822-834.

53. Garg J, Arun P, Chavan BS. Comparative efficacy of methylphenidate and atomoxetine in oppositional defiant disorder comorbid with attention deficit hyperactivity disorder. Int J Appl Basic Med Res. 2015;5(2) 114-118.

54. Cheng JY, Chen RY, Ko JS, Ng EM. Efficacy and safety of atomoxetine for attention-deficit/hyperactivity disorder in children and adolescentsmeta-analysis and meta-regression analysis. Psychopharmacology (Berl). 2007;194(2):197-209.

55. Wehmeier PM, Schacht A, Dittmann RW, et al. Effect of atomoxetine on quality of life and family burden: results from a randomized, placebocontrolled, double-blind study in children and adolescents with ADHD and comorbid oppositional defiant or conduct disorder. Qual Life Res. 2011;20(5):691-702

56. Waxmonsky JG, Waschbusch DA, Akinnusi O, Pelham WE. A comparison of atomoxetine administered as once versus twice daily dosing on the school and home functioning of children with attentiondeficit/hyperactivity disorder. J Child Adolesc Psychopharmacol. 2011; 21(1):21-32

57. van Wyk GW, Hazell PL, Kohn MR, Granger RE, Walton RJ. How oppositionality, inattention, and hyperactivity affect response to atomoxetine versus methylphenidate: a pooled meta-analysis. J Atten Disord. 2012;16(4):314-324.
58. Wehmeier PM, Kipp L, Banaschewski T, Dittmann RW, Schacht A Does comorbid disruptive behavior modify the effects of atomoxetine on ADHD symptoms as measured by a continuous performance test and a motion tracking device? J Atten Disord. 2015;19(7):591-602.

59. Ercan ES, Akyol Ardic U, Kabukcu Basay B, Ercan E, Basay O. Atomoxetine response in the inattentive and combined subtypes of attention deficit hyperactivity disorder: a retrospective chart review. Atten Defic Hyperact Disord. 2013;5(4):377-385.

60. Kaplan S, Heiligenstein J, West S, et al. Efficacy and safety of atomoxetine in childhood attention-deficit/hyperactivity disorder with comorbid oppositional defiant disorder. J Atten Disord. 2004;8(2):45-52.

61. Hazell P, Zhang S, Wolanczyk T, et al. Comorbid oppositional defiant disorder and the risk of relapse during 9 months of atomoxetine treatment for attention-deficit/hyperactivity disorder. Eur Child Adolesc Psychiatry. 2006;15(2):105-110.

62. Scott NG, Ripperger-Suhler J, Rajab MH, Kjar D. Factors associated with atomoxetine efficacy for treatment of attention-deficit/hyperactivity disorder in children and adolescents. J Child Adolesc Psychopharmacol. 2010;20(3):197-203.

63. Bangs ME, Emslie GJ, Spencer TJ, et al; Atomoxetine ADHD and Comorbid MDD Study Group. Efficacy and safety of atomoxetine in adolescents with attention-deficit/hyperactivity disorder and major depression. J Child Adolesc Psychopharmacol. 2007;17(4):407-420.

64. Wietecha L, Williams D, Shaywitz S, et al. Atomoxetine improved attention in children and adolescents with attention-deficit/hyperactivity disorder and dyslexia in a 16 week, acute, randomized, double-blind trial. J Child Adolesc Psychopharmacol. 2013;23(9):605-613.

65. de Jong CG, Van De Voorde S, Roeyers H, et al. Differential effects of atomoxetine on executive functioning and lexical decision in attentiondeficit/hyperactivity disorder and reading disorder. $J$ Child Adolesc Psychopharmacol. 2009;19(6):699-707.

66. Sumner CR, Gathercole S, Greenbaum M, et al. Atomoxetine for the treatment of attention-deficit/hyperactivity disorder (ADHD) in children with ADHD and dyslexia. Child Adolesc Psychiatry Ment Health. 2009;3:40

67. Shaywitz BA, Williams DW, Fox BK, Wietecha LA. Reading outcomes of children and adolescents with attention-deficit/hyperactivity disorder and dyslexia following atomoxetine treatment. J Child Adolesc Psychopharmacol. 2014;24(8):419-425.

68. Arnold LE, Aman MG, Cook AM, et al. Atomoxetine for hyperactivity in autism spectrum disorders: placebo-controlled crossover pilot trial. J Am Acad Child Adolesc Psychiatry. 2006;45(10):1196-1205.

69. Harfterkamp M, van de Loo-Neus G, Minderaa RB, et al. A randomized double-blind study of atomoxetine versus placebo for attention-deficit/ hyperactivity disorder symptoms in children with autism spectrum disorder. J Am Acad Child Adolesc Psychiatry. 2012;51(7):733-741.

70. Harfterkamp M, Buitelaar JK, Minderaa RB, van de Loo-Neus G, van der Gaag RJ, Hoekstra PJ. Long-term treatment with atomoxetine for attention-deficit/hyperactivity disorder symptoms in children and adolescents with autism spectrum disorder: an open-label extension study. J Child Adolesc Psychopharmacol. 2013;23(3):194-199.

71. Troost PW, Steenhuis MP, Tuynman-Qua HG, et al. Atomoxetine for attention-deficit/hyperactivity disorder symptoms in children with pervasive developmental disorders: a pilot study. $J$ Child Adolesc Psychopharmacol. 2006;16(5):611-619.

72. Fernández-Jaén A, Fernández-Mayoralas DM, Calleja-Pérez B, MuñozJareño N, Campos Díaz MR, López-Arribas S. Efficacy of atomoxetine for the treatment of ADHD symptoms in patients with pervasive developmental disorders: a prospective, open-label study. J Atten Disord. 2013; 17(6):497-505.

73. Jou RJ, Handen BL, Hardan AY. Retrospective assessment of atomoxetine in children and adolescents with pervasive developmental disorders. J Child Adolesc Psychopharmacol. 2005;15(2):325-330.

74. Posey DJ, Wiegand RE, Wilkerson J, Maynard M, Stigler KA, McDougle CJ. Open-label atomoxetine for attention-deficit/hyperactivity disorder symptoms associated with high-functioning pervasive developmental disorders. J Child Adolesc Psychopharmacol. 2006;16(5): 599-610. 
75. Charnsil C. Efficacy of atomoxetine in children with severe autistic disorders and symptoms of ADHD: an open-label study. J Atten Disord. 2011;15(8):684-689.

76. Sangal RB, Owens J, Allen AJ, Sutton V, Schuh K, Kelsey D. Effects of atomoxetine and methylphenidate on sleep in children with ADHD. Sleep. 2006;29(12):1573-1585.

77. Thurstone C, Riggs PD, Salomonsen-Sautel S, Mikulich-Gilbertson SK. Randomized, controlled trial of atomoxetine for attention-deficit/hyperactivity disorder in adolescents with substance use disorder. J Am Acad Child Adolesc Psychiatry. 2010;49(6):573-582.

78. Allen AJ, Kurlan RM, Gilbert DL, et al. Atomoxetine treatment in children and adolescents with ADHD and comorbid tic disorders. Neurology. 2005;65(12):1941-1949.

79. Spencer TJ, Sallee FR, Gilbert DL, et al. Atomoxetine treatment of ADHD in children with comorbid Tourette syndrome. J Atten Disord. 2008;11(4):470-481.

80. Adler LA, Rubin R, Qiao M, Heinloth AN, Durell TM. Patient characteristics and treatment response to atomoxetine in adults with ADHD versus ADHD comorbid with social anxiety disorder. J ADHD Relat Disord. 2010;1(3):5-15.

81. Adler LA, Liebowitz M, Kronenberger W, et al. Atomoxetine treatment in adults with attention-deficit/hyperactivity disorder and comorbid social anxiety disorder. Depress Anxiety. 2009;26(3):212-221.

82. Donnelly CL, Adler LA, Qiao M, Durell TM. Anxiety response to atomoxetine in patients with attention-deficit/hyperactivity disorder and comorbid anxiety. Poster presented at: 23rd Annual U.S. Psychiatric and Mental Health Congress (USPMHC); November 18, 2010; Orlando, FL.

83. Ravindran LN, Kim DS, Letamendi AM, Stein MB. A randomized controlled trial of atomoxetine in generalized social anxiety disorder. J Clin Psychopharmacol. 2009;29(6):561-564.

84. Gabriel A, Violato C. Adjunctive atomoxetine to SSRIs or SNRIs in the treatment of adult ADHD patients with comorbid partially responsive generalized anxiety (GA): an open-label study. Atten Defic Hyperact Disord. 2011;3(4):319-326.

85. Young JL, Sarkis E, Qiao M, Wietecha L. Once-daily treatment with atomoxetine in adults with attention-deficit/hyperactivity disorder: a 24-week, randomized, double-blind, placebo-controlled trial. Clin Neuropharmacol. 2011;34(2):51-60.

86. Durell TM, Adler LA, Williams DW, et al. Atomoxetine treatment of attention-deficit/hyperactivity disorder in young adults with assessment of functional outcomes: a randomized, double-blind, placebo-controlled clinical trial. J Clin Psychopharmacol. 2013;33(1):45-54.

87. Wilens TE, Adler LA, Weiss MD, et al; Atomoxetine ADHD/SUD Study Group. Atomoxetine treatment of adults with ADHD and comorbid alcohol use disorders. Drug Alcohol Depend. 2008;96(1-2): $145-154$.

88. Wilens TE, Adler LA, Tanaka Y, et al. Correlates of alcohol use in adults with ADHD and comorbid alcohol use disorders: exploratory analysis of a placebo-controlled trial of atomoxetine. Curr Med Res Opin. 2011;27(12):2309-2320.

89. Benegal V, Viswanath B, Narayanaswamy JC, et al. The efficacy of atomoxetine as adjunctive treatment for co-morbid substance use disorders and externalizing symptoms. Asian J Psychiatry. 2013;6(6):544-547.

90. Adler LA, Guida F, Irons S, Shaw DM. Open label pilot study of atomoxetine in adults with ADHD and substance use disorder. J Dual Diagn. 2010;6(3-4):196-207.

91. Levin FR, Mariani JJ, Secora A, et al. Atomoxetine treatment for cocaine abuse and adult attention-deficit hyperactivity disorder (ADHD): a preliminary open trial. J Dual Diagn. 2009;5(1):41-56.

92. McRae-Clark AL, Carter RE, Killeen TK, Carpenter MJ, White KG, Brady KT. A placebo-controlled trial of atomoxetine in marijuanadependent individuals with attention deficit hyperactivity disorder. Am J Addict. 2010;19(6):481-489.

93. Liu X, Kubilis P, Xu D, Bussing R, Winterstein AG. Psychotropic drug utilization in children with concurrent attention-deficit/hyperactivity disorder and anxiety. J Anxiety Disord. 2014;28(6):530-536.
94. Kuhne M, Schachar R, Tannock R. Impact of comorbid oppositional or conduct problems on attention-deficit hyperactivity disorder. J Am Acad Child Adolesc Psychiatry. 1997;36(12):1715-1725.

95. Becker SP, Marshall SA, McBurnett K. Sluggish cognitive tempo in abnormal child psychology: an historical overview and introduction to the special section. J Abnorm Child Psychol. 2014;42(1):1-6.

96. Owens J, Sangal RB, Sutton VK, Bakken R, Allen AJ, Kelsey D. Subjective and objective measures of sleep in children with attentiondeficit/hyperactivity disorder. Sleep Med. 2009;10(4):446-456.

97. Tsang TW, Kohn MR, Efron D, et al. Anxiety in young people with ADHD: clinical and self-report outcomes. J Atten Disord. 2015; 19(1):18-26.

98. Clemow DB, Walker DJ. The potential for misuse and abuse of medications in ADHD: a review. Postgrad Med. 2014;126(5):64-81.

99. Hutchison SL, Ghuman JK, Ghuman HS, Karpov I, Schuster JM. Efficacy of atomoxetine in the treatment of attention-deficit hyperactivity disorder in patients with common comorbidities in children, adolescents and adults: a review. Ther Adv Psychopharmacol. 2016;6(5):317-334.

100. Walker DJ, Mason O, Clemow DB, Day KA. Atomoxetine treatment in adults with attention-deficit/hyperactivity disorder. Postgrad Med. 2015;127(7):686-701.

101. Jerrell JM, McIntyre RS, Park YM. Risk factors for incident major depressive disorder in children and adolescents with attention-deficit/ hyperactivity disorder. Eur Child Adolesc Psychiatry. 2015;24(1): 65-73.

102. McIntyre RS, Kennedy SH, Soczynska JK, et al. Attention-deficit/ hyperactivity disorder in adults with bipolar disorder or major depressive disorder: results from the international mood disorders collaborative project. Prim Care Companion J Clin Psychiatry. 2010;12(3):e1-e7.

103. Dell'Osso B, Palazzo MC, Oldani L, Altamura AC. The noradrenergic action in antidepressant treatments: pharmacological and clinical aspects. CNS Neurosci Ther. 2011;17(6):723-732.

104. Chouinard G, Annable L, Bradwejn J. An early phase II clinical trial of tomoxetine (LY139603) in the treatment of newly admitted depressed patients. Psychopharmacology (Berl). 1984;83(1):126-128.

105. Blier P. Psychopharmacology for the Clinician Psychopharmacologie pratique. J Psychiatry Neurosci. 2006;31(4):288.

106. Michelson D, Adler LA, Amsterdam JD, et al. Addition of atomoxetine for depression incompletely responsive to sertraline: a randomized, double-blind, placebo-controlled study. J Clin Psychiatry. 2007;68(4): 582-587.

107. Cortese S, Holtmann M, Banaschewski T, et al; European ADHD Guidelines Group. Practitioner review: current best practice in the management of adverse events during treatment with ADHD medications in children and adolescents. J Child Psychol Psychiatry. 2013;54(3): 227-246.

108. National Institute for Health and Care Excellence. Clinical guideline 72: attention deficit hyperactivity disorder: diagnosis and management of ADHD in children, young people and adults. 2013.

109. Katusic SK, Barbaresi WJ, Colligan RC, Weaver AL, Leibson CL, Jacobsen SJ. Psychostimulant treatment and risk for substance abuse among young adults with a history of attention-deficit/hyperactivity disorder: a population-based, birth cohort study. $J$ Child Adolesc Psychopharmacol. 2005;15(5):764-776.

110. Kollins SH. A qualitative review of issues arising in the use of psychostimulant medications in patients with ADHD and co-morbid substance use disorders. Curr Med Res Opin. 2008;24(5):1345-1357.

111. Upadhyaya HP, Desaiah D, Schuh KJ, et al. A review of the abuse potential assessment of atomoxetine: a nonstimulant medication for attention-deficit/hyperactivity disorder. Psychopharmacology (Berl). 2013;226(2):189-200

112. Wolraich M, Brown L, Brown RT, et al; Subcommittee on AttentionDeficit/Hyperactivity Disorder; Steering Committee on Quality Improvement and Management. ADHD: clinical practice guideline for the diagnosis, evaluation, and treatment of attention-deficit/hyperactivity disorder in children and adolescents. Pediatrics. 2011;128(5):1007-1022. 
113. Pliszka S; AACAP Work Group on Quality Issues. Practice parameter for the assessment and treatment of children and adolescents with attentiondeficit/hyperactivity disorder. J Am Acad Child Adolesc Psychiatry. 2007;46(7):894-921.

114. Brewerton TD, Duncan AE. Associations between attention deficit hyperactivity disorder and eating disorders by gender: results from the national comorbidity survey replication. Eur Eat Disord Rev. 2016; 24(6):536-540.
115. Asherson P, Young AH, Eich-Höchli D, Moran P, Porsdal V, Deberdt W. Differential diagnosis, comorbidity, and treatment of attention-deficit/ hyperactivity disorder in relation to bipolar disorder or borderline personality disorder in adults. Curr Med Res Opin. 2014;30(8): 1657-1672.

\section{Publish your work in this journal}

Neuropsychiatric Disease and Treatment is an international, peerreviewed journal of clinical therapeutics and pharmacology focusing on concise rapid reporting of clinical or pre-clinical studies on a range of neuropsychiatric and neurological disorders. This journal is indexed on PubMed Central, the 'PsycINFO' database and CAS, and is the official journal of The International Neuropsychiatric Association (INA). The manuscript management system is completely online and includes a very quick and fair peer-review system, which is all easy to use. Visit http://www.dovepress.com/testimonials.php to read real quotes from published authors.

Submit your manuscript here: http://www.dovepress.com/neuropsychiatric-disease-and-treatment-journal 